\title{
The Effect of Pre-reading Activities on the Comprehension of L2 Texts by Iranian Pre-intermediate EFL Learners
}

\author{
Roghayeh Rasouli \\ Department of English Language, Rasht Branch, Islamic Azad University, Rasht, Iran \\ E-mail: R54.rasooli@gmail.com
}

\begin{abstract}
Akhtar Zohouri Vaghei
Department of English Language, Rasht Branch, Islamic Azad University, Rasht, Iran E-mail: zohouri@iaurasht.ac.ir
\end{abstract}

\begin{abstract}
Majid Pourmohammadi Ph.D (Corresponding author)
Assistant Professor in TESOL, Department of English Language, College of Humanities, Rasht Branch, Islamic Azad University, Rasht, Iran E-mail: pourmohammad@iaurasht.ac.ir
\end{abstract}

Received: May 7, 2019 Accepted: June 11, $2019 \quad$ Published: August 1, 2019

doi:10.5296/jse.v9i3.14852ＵRL: https://doi.org/10.5296/jse.v9i3.14852

\begin{abstract}
This present study investigated the effects of pre-reading activities on the reading comprehension ability of Iranian pre-intermediate level EFL learners. To this end, 40 female EFL learners with the age of 14 to 18 who were studying at Soroush English Institute in Rasht, Iran were selected from a larger population based on their performance on a Quick Placement Test. Then the participants were randomly assigned to one experimental and one control group. A pretest piloted before with the reliability index of .86 was administered to both groups. Next, the experimental group received 10 sessions treatment that was vocabulary pre-teaching. Meanwhile, the control group received its usual classroom teaching. Then, a posttest with the reliability index of .88 was administered to both groups. The result of this study revealed that experimental group who received the new treatment achieved
\end{abstract}




\section{Macrothink}

Journal of Studies in Education

ISSN 2162-6952 2019, Vol. 9, No. 3

higher proficiency in reading comprehension than the control group. Therefore, the result of this study confirmed that pre-reading activities and vocabulary pre-teaching can statistically improve the participants' reading comprehension ability.

Keywords: pre-reading activities, reading comprehension, EFL learners 


\section{Introduction}

Nowadays English learning is essential because English is the international communication medium. The language is necessary for different activities, including education, politics, and socio-economics (Mckay, 2002). It emphasizes the need for curriculum and teaching process revision in order to prepare student for real life application in the information age. The teaching should accommodate the learners' development of the four language skills.

Sookchotirat (2005) suggested that reading skill is the most important skill as it is the basis of all the success in one's life. Good readers can gain more knowledge of any kind from reading. Reading makes the readers more knowledgeable, with wider perspectives and vision. Reading helps the reader get new ideas leading to cognitive development. When the readers transfer what they read to apply with their own ideas, a new perspective or idea is created.

Reading as a form of language input has been considered as one of the most important skills in the area of language learning and teaching (Rouhi \& Negari, 2012). According to Nunan (2003, p. 69), "with strengthened reading skills, learners will learn greater progress and development in all other areas of learning".

Vocabulary knowledge is only part of language structures that plays a significant role in reading comprehension. It means learners will not be able to comprehend texts including so many unfamiliar vocabulary. According to Gibbons (2002, p. 83), "once the learners have learnt to identify the main idea of the text, vocabulary items which cause difficulties in comprehending the text, have to be identified and worked on". Language teachers and researchers have to be aware of the importance of knowing vocabulary before reading texts in EFL classrooms.

\subsection{Statement of the Problem}

Learning English as a foreign language is, undoubtedly, a complex and difficult process and comprehension is the ultimate goal of teaching reading. Students' obstacles in reading comprehension may be partially attributed to nonlinguistic factors such as lack of motivation and interest.

According to Gibbons (2002, p. 83), "being unfamiliar with the language in the text makes it almost impossible to what will come next. Therefore, readers who do not recognize the meaning of words will have difficulty comprehending the text and will miss the opportunity to learn new words".

Reading comprehension is the essence and goal of reading, since the purpose of all reading is to gather meaning from the printed page. If a student says words in a passage without getting their meaning, he or she would hesitate to read it again. For many learning- disabled students, reading comprehension is a major problem which is based on many reasons: Maybe the person has a language problem. Language has an important role in reading. One cannot read a book without knowing that language. If a student's knowledge of English is poor, then his reading will be poor, and naturally his reading comprehension. The other reason might be based on basic skills of reading which have not been automatized yet. Therefore, such a 
student whose foundational skill of reading has not yet become automatic, will read uncertainly and with great difficulty. The poor reader is forced all his concentration to word recognition, and therefore has "no concentration left" to decode the written word, and as a result he will not be able to read with comprehension. Decoding of the written word is so important aspect of the reading act. That without it, reading comprehension would be impossible.

\subsection{Significance of the Study}

There are a lot of methods and strategies for reading comprehension in EFL classes. Pre-reading activities cover a range of possibilities, all directed at helping learners engage in a process of discovery and to feel authorized to engage with the form and content of the text. What all successful pre-reading activities have in common is that they are student-centered. The instructor has to identify the potential problems, and then has to help students find ways to surmount those difficulties.

One of the important methods of improving reading comprehension can be vocabulary pre-teaching. Vocabulary learning is an essential part in foreign language learning as the meaning of new words are very often emphasized, whether in books or in classrooms. It is also central to language teaching and is of paramount importance to a language learner (Berne \& Blachowicz, 2008).

Teaching words is a crucial aspect in learning a language as languages are based on words. It is almost impossible to learn a language without words; even when the goal of language is not communication - but creating emotion and images, still the power of words does matter. Both teachers and students agree that acquisition of the vocabulary is a central factor in teaching a language (Walters, 2004).

\subsection{Objectives of the Study}

Nowadays many experts work on different parts of the language. They try to facilitate the teaching and learning of each specific part. There are many studies which work on different tasks and their advantages and disadvantages. One of the goals of pre-reading strategies is to activate the reader's prior knowledge. Some of these strategies are brainstorming, group discussion, concept of mind mapping, pre questioning and so on.

Reading activities refer to any activity that classroom instructors use to help the learner bring their prior knowledge to connect with new information they experience in the reading in order to get the most understanding of the message in the reading material. Reading comprehension refers to the learners' level of reading comprehension ability.

This study aims to measure the effect of pre-reading activities such as vocabulary pre-teaching on learners' reading comprehension ability, which is so essential in the area of teaching English. As it has been maintained, vocabulary knowledge has a significant impact on various skills and acquisition of vocabulary is a central factor in teaching any language (Walters, 2004). 


\subsection{Research Questions}

There are two main specific research questions addressed in this study:

1. Does pre-reading activities have any statistically significant effect on Iranian pre-intermediate EFL learners' reading comprehension ability?

2. Does vocabulary pre-teaching task have any statistically significant effect on Iranian pre-intermediate EFL learners' reading comprehension ability?

\section{Literature Review}

Reading comprehension refers to the ability to understand information presented in written form. While this process usually entails understanding textbook assignment, reading comprehension skills also may affect one's interpretation of direction on examination, homework and completion of job applications or questionnaires. Many students still have problems with their reading comprehension because they are unable to accurately understand written materials. That is, they cannot interpret what they read and make the connection between what they read and what they have already known.

Reading comprehension is the process of constructing meaning from text. The ultimate goal of this process is to obtain a general understanding of the full text rather than to translate the words one by one. Grabe and Stoller (2011) believe that general reading comprehension is the most important objective for reading. Furthermore, they point out that general reading comprehension is enormously complex. The main goal of reading is reading for comprehension. Moreover, raising learner awareness of main ideas in a text and exploring the organization of a text are necessary for comprehension (Grabe, 2002).

Hardebeck (2006) defines reading comprehension strategies as tools or plans for facilitating and extending comprehension. Reading comprehension strategies can help readers remember the key points, distinguish the necessary and unnecessary information, think about the main idea and comment on the subject matter. They can learn reading strategies that enable them to read at much higher levels of proficiency.

Nation (2001) describes the relationship between vocabulary knowledge and language use as complementary: knowledge of vocabulary enables language use and, conversely, language use leads to an increase in vocabulary knowledge.

Many studies suggest that pre-reading activities have a facilitative effect in text comprehension, and that teachers can use them to provide and/or activate necessary background knowledge relevant to understanding the new text. Pre-reading activities are intended to activate appropriate knowledge structures or provide the knowledge that the reader lacks. 


\section{MlMacrothink}

\section{Methodology}

\subsection{Participants}

The participants involved two groups of students who were studying English as their foreign language at Soroush Institute in Rasht, Iran. The total number of learners who took QPT (Quick Placement Test) was 67 and the participants whose scores fell within 30 to 45 were selected as the sample of this study. They were identified as pre-intermediate level EFL learners based on QPT. They were between 14 to 18 years old. All of them were high school students. This sample included 40 students. They were divided into the treatment group and the control group. The treatment group received the new proposed approach, pre-training vocabulary. The words were introduced by the teacher by writing them down on the board, defining them and giving an example for each and the control group was taught without any pre-reading activities. The students were asked to read first, then guess the meaning and find new words in their monolingual dictionaries.

\subsection{Pilot Study}

Prior to conducting the pretest and posttest for the target participants, they were administered to two groups including 10 pre-intermediate EFL learners with the same characteristics of the target sample. The pretest and posttest were piloted to inform the researcher about the possible problems of instruments and to avoid wasting time with the participants selected inappropriately. All of the steps as mentioned in the design of the study were done for these groups. The participants of these groups were tested by some reading comprehension tasks and they did not receive the mentioned treatment (pre-training vocabulary). At first, they answered QPT. Then pretest and posttest were taken. Moreover, the reliability of pretest and posttest of reading comprehension was calculated and it was acceptable according to reliability standards.

\subsection{Pretest}

A pretest was administered before the treatments to determine the initial differences existing among the groups with respect to their reading comprehension ability. The reading test that was administered to the learners as a pretest included 35 items.

\subsection{Posttest}

In the end, a posttest that was completely different to the pretest was given to the participants. The aim of different posttest was controlling the possible testing effect. The posttest was taken after completing the treatment. The goal of the posttest is to find out the effect and strength of new treatment on students' reading comprehension.

\subsection{Procedures for Data Collection and Analysis}

At first, QPT was administered to make clear the level of the participants and to make sure that the participants were homogenous who were studying English as a foreign language at Soroush English Institute in Rasht, Iran. 


\section{Al Macrothink}

Before giving a pretest to the main participants, a pilot study was carried out. The pretest was given to 10 pre-intermediate level learners with the same characteristics of the target sample in order for the researcher to predict the potential problems of instruments and to make sure that the time was not being wasted with inappropriate participants. Then, a reading comprehension pretest was administered between the experimental and control group in order to find out the potential initial differences of the participants' reading comprehension ability. The new vocabulary was introduced to the participants of the treatment group before starting the reading process. The students were familiarized with the context of the reading task and the words they would read during the task, whereas the comparison group received no treatment. They just read the text and answered the questions.

The final stage was the posttest. After carrying out the treatments, a posttest was given to the participants in order to scrutinize the results and to measure the progress from pretest to posttest and the effectiveness of the treatments in the experimental group. Notably, the posttest was the same as the pretest except for the arrangement of the items. The aim of designing a small rearrangement of the items was controlling the potential testing effect. The delayed posttest was taken to make sure that the proposed method is effective after a longer period of time.

\section{Results}

\subsection{Data Analysis and Findings}

At first, it was important to calculate the test reliability. The reliability of 35 items of the reading comprehension ability tests determined value of Cronbach alpha equaled .862 , in the pretest and reliability .889 , in the posttest which was acceptable based on the reliability standard. The test results are presented in Table 1.

Table 1. Reliability Statistics for the reading comprehension ability test

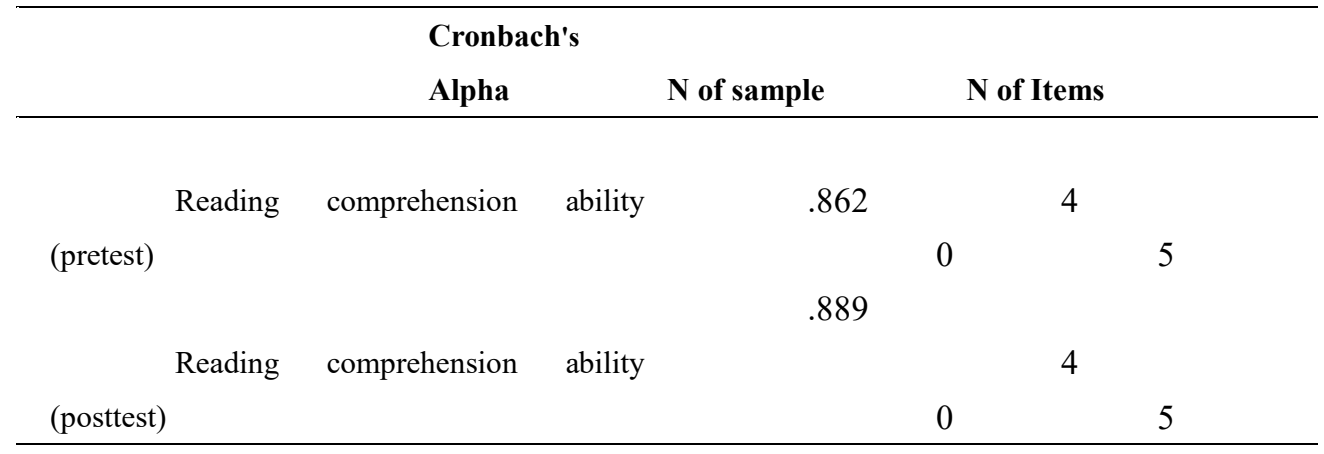

\subsection{Inferential Analysis of the Data}

To determine whether there is a difference between the two groups, T-Test for independent samples was run on the pre and posttest scores of the two groups. Before implementing $\mathrm{T}$-Test analysis, Leven test for condition equality of the variances was investigated. Levene's test of equality of error variances is presented in Tables 2 and 3 
Table 2. Levene's test of equality of error variances in pretest

\begin{tabular}{llll}
\hline Df1 & Df2 & Sig. \\
\hline 1 & 38 & .94
\end{tabular}

Table 3. Levene's test of equality of error variances in posttest

\begin{tabular}{llll}
\hline $\mathbf{F}$ & Df1 & Df2 & Sig. \\
\hline 14.50 & 1 & 38 & .89 \\
\hline
\end{tabular}

The Levene's test assumes the equality of the variances. This is a test that determines if the two variables have about the same or different amounts of variability between scores. Accordingly, the significance level came to .94 in pretest and .89 in posttest, which is larger than the .05 value. This means that there is a statistically significant relation between two conditions.

Table 4. T-Test for different groups in pretest

\begin{tabular}{|c|c|c|c|c|c|c|c|}
\hline \multicolumn{3}{|c|}{ Source } & \multicolumn{4}{|c|}{ Mea } & \multirow[t]{2}{*}{$\bar{s}$} \\
\hline & & & f & n Difference & & ig. & \\
\hline & Equal & variances & &.$/ 12$ & & & \\
\hline assumed & & & 8 &.$/ 12$ & $/ 69$ & $/ 61$ & \\
\hline & Equal & variances not & & & & & \\
\hline assumed & & & $7 / 98$ & & $/ 69$ & $/ 61$ & \\
\hline
\end{tabular}

Table 4 shows that the mean scores difference of the experimental group and the control groups by $\mathrm{T}$ test for independent samples analyze is equal and the two groups did not perform differently in terms of their mean scores.

Table 5. T-Test for different groups in posttest

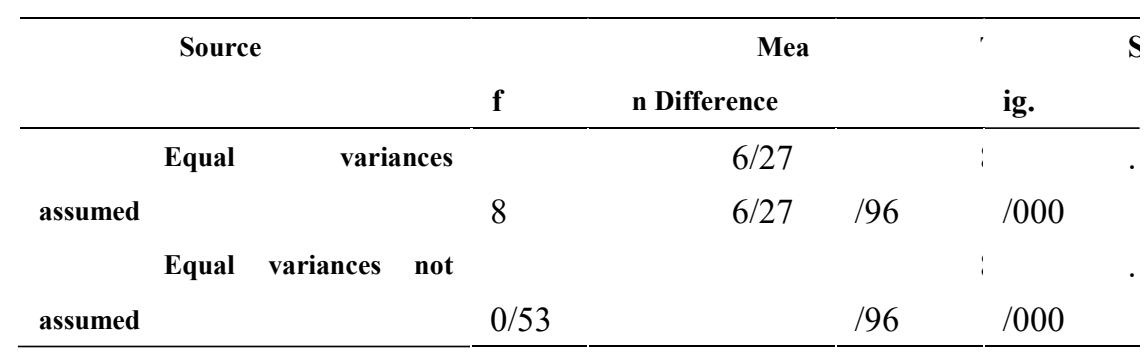

As it can be seen from Table 5, the mean scores difference of the experimental group and the control groups by $\mathrm{T}$ test for independent samples analyze is not equal. It is clearly shown that the experimental group who received 10-session treatment that included vocabulary pre-teaching performed better than the control group who received traditional method. 


\section{I Macrothink}

Table 6. Paired sample t-test for different control group in pretest and posttest

\begin{tabular}{ccccc}
\hline Source & & Mea & ' & s \\
& & $\mathbf{n}$ & & ig. \\
\hline Pretest & & $10 / 93$ & & \\
& & $11 / 28$ & & \\
Posttest & & & $/ 67$ & $/ 110$ \\
& 0 & & & \\
\hline
\end{tabular}

Table 6 illustrates that the mean scores difference of the control groups by $T$ test for paired sample t-test analyze is equal and learners did not perform differently in terms of their mean scores in pre and posttest.

Table 7. Paired sample t-test for different experimental group in pretest and posttest

\begin{tabular}{ccccc}
\hline Source & & Mea & & s \\
& & $\mathbf{n}$ & & ig. \\
\hline Pretest & 0 & $11 / 05$ & & \\
& & $17 / 55$ & 1 & \\
Posttest & & & $/ 69$ & $/ 000$ \\
& 0 & & & \\
\hline
\end{tabular}

Table 7 reveals that the mean scores difference of the experimental groups by $\mathrm{T}$ test for paired sample t-test analyze is not equal in pre and posttest and learners performed better in terms of their mean scores in posttest after received 10 -session treatment.

\section{Discussion}

The prominent point about this study was analyzing the effectiveness of the pre-reading vocabulary pre teaching on reading comprehension of Iranian pre-intermediate level EFL learners who studied at Soroush English Institute in Rasht, Iran.

To further investigate the effectiveness of vocabulary pre-teaching on reading comprehension ability at pre-intermediate level, this study aimed to examine whether vocabulary pre-teaching as a kind of pre-reading activities would affect the ability of reading comprehension among Iranian EFL pre-intermediate level students.

As it was mentioned before, there was no significant difference between the groups at the reading comprehension pretest, whereas there were crucial differences between them at posttest. These differences mostly were between the pretest and the posttest of the experimental group not control group. Thus, these differences may be referred to pre teaching of vocabulary before reading a text. The mean score obtained by two groups on the reading comprehension posttest indicated that the experimental group obtained higher mean score; however, the control group obtained the same mean score as pretest.

The findings of this study are in line with several relevant studies. It means the results of current study verify the results of previous studies which focus on the effectiveness of different pre-reading activities on reading comprehension of Iranian EFL learners. Yusuf 
(2011) examined the impact of pre-reading activities on senior secondary students' reading comprehension. The result indicated that the experimental group which was exposed to pre-reading activities gained considerably in performance in reading comprehension tasks than the control group. The experimental group performed much better than the control group in the posttest.

The results are also in agreement with the one carried out by Yeeding (2007) who investigated the effects of pre-reading activities on learners' motivation and reading comprehension ability. Results showed that the activities subjects were highly motivated, enthusiastic to read. After the experiment, they scored significantly higher.

Moreover, this study is congruent with the one conducted by Thongyon and Chiramanee (2011) who investigated the effect of two types of pre-reading activity on the learners' reading comprehension ability. The two pre-reading activities implemented were guessing story content by pictures and pre-reading questioning activities. It was found that both subject groups performed significantly better on the posttest than the pretest.

\section{Conclusion}

This study attempted to determine the impact of pre-reading activities vocabulary pre teaching approach in improving reading comprehension of pre-intermediate EFL learners. Through this study, the experimental group verified beneficial effect of vocabulary pre teaching in reading comprehension and participants of this group scored higher in the posttest than the pretest. In other words, vocabulary pre-teaching approach leads to more proficiency in reading comprehension among Iranian pre-intermediate EFL learners. Hence, all the null hypotheses proposed at the beginning of the study were rejected. When observing the data the students in the experimental group who got new treatment averaged higher scores in compare with the students in the control group who did not get new treatment. Overall, this study recommends applying vocabulary pre teaching approach in EFL contexts where there are limited opportunities for learners to use the target language outside the classrooms to help them to acquire more proficiency in reading comprehension.

\section{Reference}

Gibbons, P. (2002). Scaffolding language scaffolding learning: Teaching second language learners in the mainstream classroom. USA, Portsmouth: Heinemann.

Grabe, W. (2002). Reading in a second language. In R. B. Kaplan (Ed.), The Oxford handbook of applied linguistics (pp. 49-59). Oxford: Oxford University Press.

Grabe, W., \& Stoller, F. L. (2011). Teaching and researching reading. In C. N. Candlin, \& D. R. Hall (Eds.), Applied linguistics in action series. Harlow: Pearson. https://doi.org/10.1002/9781405198431.wbeal1174

Graves, M., F., Watts, S., M., \& Graves, B., B. (1994). Essentials of classroom teaching elementary reading methods. U.S.A.: Allyn and Bacon. 


\section{Macrothink}

Journal of Studies in Education

ISSN 2162-6952

2019, Vol. 9, No. 3

Hardebecek, M. M. (2006). Effectiveness and usage of reading comprehension strategies for second grade title 1 students. (M.A. Thesis), Minesota State University, Education Department, Minnesota.

Mckey, S. L. (2002). Teaching English as an international language. rethinking goals and approaches. Oxford University Press.

Nation, I. S. P. (2001). Learning vocabulary in another language. Cambridge, UK: Cambridge University Press. https://doi.org/10.1017/CBO9781139524759

Nunan, D. (2003). Second language teaching and learning. Boston, Massachusetts: Heinle \& Heinle Publishers.

Rouhi, M., \& Negari, G. M. (2012). EFL learners' vocabulary knowledge and its role in their reading comprehension performance. English Language Teaching, 1(2), 39-48.

Sookchotirat, M. (2005). Reading: Learning sooner, teaching well. Nanmee, Bangkok, Thailand.

Thongyon, P., \& Chiramanee, T. (2011). The effects of pre-reading activities on reading comprehension ability. Songkla University.

Walters, J. M. (2004). Teaching the use of context to infer meaning: A longitudinal survey of L1 and L2 vocabulary research. Language Teaching, 37(4), 243-252. https://doi.org/10.1017/S0261444805002491

Yeeding, S. (2007). Using pre-reading activities to increase learners' motivation in reading comprehension. A case of 2nd year vocational students enrolled in the Electrical and Electronic Certificate Program at Industrial Technology College, King Mongkut, Pranakorn.

Yusuf, H. O. (2011). The effect of pre-reading activities on students' performance in reading comprehension in senior secondary schools. Ahmadu Bello University Samaru- Zaria. 